Jean-Baptiste Gouyon

Post-doctoral research fellow, Max Planck Institute for the History of Science, Berlin

This text is a post-peer-review, pre-copyedit version of an article to be published in History of Science. 


\title{
THE BBC NATURAL HISTORY UNIT: INSTITUTING NATURAL HISTORY FILM-MAKING IN BRITAIN
}

\author{
Jean-Baptiste Gouyon \\ Max Plank Institute for the History of Science, Berlin
}

\begin{abstract}
"Cameras have revealed how elephants are able to get a drink of fresh water when faced with a stagnant waterhole.

A BBC team discovered that the tusked giants use their trunks to delicately siphon off clean liquid that has settled at the top of the dirty pool.
\end{abstract}

The footage shows how the elephants move incredibly slowly to avoid stirring up any sediment.

The Natural History Unit team said this was the first time that they had seen this resourceful behaviour." 1

\section{INTRODUCTION}

The epigraph above, a 2009 press release from the BBC, draws the attention towards the process through which the BBC Natural History Unit (NHU) came to be able to present its natural history film-makers as discoverers and natural history footage as discoveries, thus implicitly presenting itself as a producer of genuine knowledge of the natural world, without making any mention of the activities and works of scientific practitioners. Referring to the production of knowledge in the field, Henrika Kuklick and Robert Kohler note: '[c]ultural 
appropriation and ambiguous identity go with the territory, so to speak, of the field sciences, ${ }^{2}$. In the specific case of the relationship between field sciences and natural history film-making, Gregg Mitman for example demonstrates the transformative power of the latter, whose conventions and constraints have been defined outside the sphere of science, on the ways 'biological knowledge gets produced and consumed'. In his study of the work of Iain Douglas-Hamilton on elephants, he suggests that adopting the narrative conventions of natural history film-making, most notably the emphasis on individual animals, lead the field biologist to create 'new systems of patronage and research' ${ }^{3}$ alien to the culture of the twentieth-century life sciences.

The historical study proposed in this paper is informed by the constructivist approach to the public understanding of science. This approach underlines the 'fluidity, porosity and constructedness of the boundaries ${ }^{34}$ between the scientific endeavour and other modes of the production of knowledge of the natural world, and invites, specifically, to examine how these boundaries are negotiated, displaced and maintained, according to the needs of social actors engaged in fashioning their identity as trustable spokespersons for the natural world, with relation to the received source of such knowledge, science. ${ }^{5}$

Two notions enable us to make sense of the way cultures of knowledge production are constituted, and claims to cognitive credibility are made and sustained; the notion of instrument and that of institution. Instruments can be seen as a material nucleus around which bearers of a given material culture can congregate and define a social space based on the expert use of the instrument in question, and from which outsiders can be excluded. In this acceptation the notion of instrument points towards the idea that matters of fact are socially 
constituted on the basis of a consensus 'in an acceptance of certain "technologies" of fact creation" ${ }^{6}$. In the same vein, institutions can be thought about as social constructs and as rhetorical devices providing social groups with resources to assert their moral authority. In particular, they can be conceived of as means to naturalize beliefs, norms and values. ${ }^{7}$ This focus on two supraindividual categories, which lead to concentrate on groups, should not, however, obscure the fact that the story told in this paper is first and foremost about individuals engaged in fashioning their personal identity.

Before the First world war and during the interwar period, early natural history film-makers, in the person, especially, of Cherry Kearton, successfully took possession of the ground left vacant by a vanishing imperial hunting elite, and established the practice of natural history film-making as a socially and morally legitimate conduct to appropriate, control, and enjoy the Empire's wilderness. In the early 1950s David Attenborough revived Kearton's project on British television and displaced, in the public eye, the Zoological Society as the bearer of authority on animals in the field. ${ }^{8}$ In this paper, focusing on the establishment of the BBC Natural History Unit (NHU), we will examine how, in the period extending from the early 1950 s to the late 1970 s, natural history filmmakers set and maintained a frontier between their practice and most notably ethology, defining the NHU as a natural history institution, able to collaborate with field researchers in the life sciences but not subservient to them. For one key feature of the period seems to have been the development of a publicly visible field science of animal behaviour. As studies in the history of ethology suggest, the formation of this discipline can be seen as a late instance of what Lynn Nyhart analyses as the fragmentation of natural history and the reshaping 
of these fragments in the various disciplines of biological sciences. ${ }^{9}$ The founders of ethology turned the observation of wild animals behaving undisturbed in the field, a grounding principle of field naturalists' practice, into the methodological cornerstone of their pursuit. As Konrad Lorenz late in his life would note, in a book destined to a wide public, 'the only way scientists can make novel, unexpected discoveries is through observation free of any preconceived notions, ${ }^{10}$. This paper will suggest that the development of natural history film-making on British television in the post-war period can be seen as an attempt by naturalists to protect their culture from the threat posed by the development of the science of ethology, "controlled by disciplined experts"11.

The 'boundary work' ${ }^{12}$ natural history film-makers at the NHU performed from the early 1950s on, focused on the notion of observation, and brought forward technologies of visualisation, television and the filming apparatus. It extended over several years and involved the making of several flagship programmes. The BBC's first step was to ensure an important and faithful public following for the practice of natural history on television by front staging the figure of a respected naturalist, Peter Scott, in the programme Look. This benefited from the social shaping, in the first years of the 1950s, of television as a technology of public witnessing, as much as it contributed to it. In the 1960s however, appeared a need to implement a new strategy. The NHU had to face competition from both scientific practitioners themselves and another television channel. In the preceding decade, Niko Tinbergen, in particular, had been actively presenting his work to the British public and the first cohorts of his Ph.D. students were now joining the chorus ${ }^{13}$. In this context of a reinforced public presence of the scientific study of animal behaviour under natural 
conditions, ITV introduced the series Survival. The programme set out to present, in an accurately simplified and entertaining fashion, the work of these field scientists. This threatened to undermine the very notion of natural history television as a practice of knowledge-production. The NHU could not solely rely on trusted naturalists anymore; it had to publicly define its links with scientific practitioners. The BBC first launched Life, a series of popularised biology hosted by ethologist Desmond Morris and featuring leading biologists. Then, it reclaimed the status of a knowledge-producer; mainly with the series The World About Us, it engaged in actively shaping the public identity of field scientists into local experts, bearers of a local knowledge who, most of the time, could not be trusted to use the camera properly to make discoveries. From then on scientific practitioners would appear as helpers, providing the $\mathrm{BBC}$ with the raw material useful to making visual objects of knowledge, the films. In this process, emphasising the mastery of film technology became central to the fashioning of the natural history film-maker's identity in contrast to the field researcher's. The shaping of the NHU as a new haven for natural history reached a climax in the series Life on Earth, presented, as we will see, as the television equivalent of the naturalist's study and reclaiming, for natural history television, the notion of universal knowledge allegedly abandoned by specialised professional science ${ }^{14}$. With Life on Earth, the process of cognitive legitimisation of natural history television became entirely self-contained, thus suggesting that the BBC NHU, producing and diffusing the series, stood as an institution able to constitute expertise of the natural world in its own right.

THE 1950S: NATURALISTS ON SCREEN - TRUTHTELLING AND TELEVISION 
The development of natural history television in the 1950s appears to have been essentially a means for amateur naturalists of giving more visibility to their practice and their beliefs. Desmond Hawkins, usually held responsible for initiating natural history television broadcasting from Bristol in 1953, was a keen amateur ornithologist, and had, since 1936, been a radio features producer at the $\mathrm{BBC}$, who revived natural history radio diffusion in the immediate post-war with several programmes such as The Naturalist (1946), Bird-song of the month (1947), or Birds in Britain (1951) —all instances of collaboration between the BBC and famous naturalists of the time ${ }^{15}$. One of them, Peter Scott (1909-1989), 'was to play the key front-of-camera role in making successful Desmond Hawkins' ventures into television, ${ }^{16}$, enabling the effective relocation on television of visual artefacts consumed during the inter-war period in cinemas, and bringing instant cognitive credibility to this new setting for natural history. Scott achieved this through his wide access to a network of naturalists who made films of animals, and through his overall standing as a gentlemanly figure, with publicly known connections with the Establishment, which reflected positively on the whole enterprise.

Made a 'Life Fellow of the Zoological Society of London as a christening present ${ }^{17}$ Peter Scott, the son of Robert Scott the polar explorer, spent three years, from 1927 to 1930 , at Trinity College in Cambridge, where he first read 'Natural Sciences, Zoology, Botany, Physiology, and [...] Geology'18, before choosing to be a wildlife painter, instead of a life scientist, mainly because he did not agree with what traditional holders of cognitive authority then considered relevant as knowledge of the natural world. 'In those days the science of animal 
behaviour had scarcely begun. To know about live animals was something less than science ${ }^{19}$.

Scott choose painting as an alternative way of relating to, and producing knowledge of wild animals, in reaction against what he felt was too restrictive a view on them. In his opinion, 1920s and 1930s British zoology, neglecting how animals integrate in their environment, was not holistic enough to generate what he believed was appropriate knowledge of the natural world. In particular, zoology, dealing with dead specimens, could not produce satisfying knowledge of movement, by contrast with painting. For the painter produced composite images: on the same canvas several birds in different postures could be represented. As Scott reminisced from the early days of his career: already I had begun to understand that the movement of birds through the air could more easily be suggested by the patterns of the flock than by the shapes of the individuals. ${ }^{20}$

Scott conceived of natural history painting as a means of producing representations which were true to nature, and whose truthfulness depended for a large part on his subjective knowledge of the birds: 'Other artists did not know them [wildfowl] quite as I knew them, ${ }^{21}$. This knowledge, in the first place sensual, originated from countless observations of birds 'at dawn or dusk or moonlight, or in storm or frost or snow ${ }^{22}$. It enabled Scott to produce images which he hoped, would transmit to viewers a sense of his experience of being in nature and move them 'in the same way as [he] was when [he] watched the flight of the wild geese, and heard their music ${ }^{23}$.

Scott's natural history painting turned out to be a success, his images rapidly becoming regular features in the magazine Country Life. Presenting himself as 'a 
painter by profession and an amateur scientist ${ }^{24}$, he certainly appeared as this archetypical figure of Victorian Britain, the gentleman of science, 'devoted to the serious pursuit of knowledge as a vocation, but not for pay ${ }^{, 25}$ and exhibiting a high degree of freedom of action, which implicitly positioned him as a truthteller $^{26}$.

Peter [Scott] never claimed to be an academic of any kind, yet seemed to know them all and talk their language [and] was able to mingle happily in the upper scientific echelons—even after daring to suggest that there really was a monster in Loch Ness. ${ }^{27}$

To make such a gentlemanly figure the face of natural history television in the early 1950s, to the extent that to television viewers 'wildlife was Look with Sir Peter Scott ${ }^{28}$, appears as a borrowing of his trustworthy status in order to lay solid grounds for the perception of natural history films as reliable sources of knowledge of the natural world.

The first natural history television programme to come out of Bristol was an outside-broadcast, live from Scott's Wildfowl Trust, an ornithological research station which also happened to be Scott's home. ${ }^{29}$ The programme presented the research work conducted there by Scott and his naturalists friends. Regular studio programmes followed from December 1953. At first Scott presented his own films, then 'Peter Scott's friends [...] [a]nyone who'd got an amateur film camera and did bird films in their holidays mostly ${ }^{30}$ came to show their films. Thus started the natural history television series Look. Every fortnight, then weekly, Scott would sit with his guest, a naturalist cameraman, in a studio set representing his own study at Slimbridge. The audience would be witness to a conversation between the two men about the film, its topic and the circumstances 
of its making, punctuated by the projection of some footage. As one contributor to this programme noted:

None of the distinguished naturalists and cinematographers whom Peter Scott has introduced talk down to their public. Indeed, they talk, not to their public, so much as to each other in the relaxed yet lucid voices that they would use in any normal discussion of their profession amongst themselves. The fact that by so doing they capture and please their audience is itself proof that natural history needs no aid to acceptance $[\ldots] .{ }^{31}$

This conversational format of presentation can perhaps be interpreted in the light of the pivotal role of conversation in elite Victorian society and the importance of knowledge of nature in this context. In mid-nineteenth century Britain, in a performative public enactment of the way knowledge was produced in the enclosure of the Royal Society of London, polite conversation had been devised as a means of 'bringing science to the center of fashionable society. [...] Objects of research became conversation pieces and brought discoveries to the attention of the fashionable world ${ }^{32}$. Genteel conversation was thus a kind of template for the public performance of the production of knowledge and in a way, the popularisation of this process amongst the upper classes. The use of this same pattern of civil conversation when discussing matters related to natural phenomena as shown in the films can similarly be seen as positioning these films as instances of genuine knowledge. To place the films at the center of this genteel conversation was thus to present them as objects of research.

This notion of genteel conversation allows us, it seems, to bring a second point to light. As we saw above, Scott clearly stated that his dissatisfaction with a 
scholarly culture which considered the knowledge of how live animals behave as 'less than science, ${ }^{33}$, was at the origin of his engagement with another mode of relationship to wild animals: painting them. The organisation of Scott's natural history programme, and the way it appeared to its audience, exhibits features resembling what has been analysed as the emergence of an English science in the $17^{\text {th }} \mathrm{C}$, which resulted in the foundation of the Royal Society of London. This movement, concerned with means of 'producing, sustaining, and modifying knowledge-claims in lay society ${ }^{34}$, mobilised for that purpose "conventions and codes of gentleman conversation [...] as practically effective solutions to problems of scientific evidence, testimony, and assent ${ }^{35}$. As Shapin emphasises such

appropriation and relocation of specific gentlemanly practices were [...] the result of new modes of participation by members of the gentle classes in natural philosophy and natural history, and of the possibilities that participation offered for legitimating and revaluing scholarly culture. ${ }^{36}$

The fact, in the case of natural history film-making, that such endeavour occurs in a context which can be identified as non-academic, can be connected to the point highlighted by several scholars that instances of non-academic knowledge-production were occasions of contesting the ruling authority of the academy and attempts at bypassing it through a direct appeal to the public. ${ }^{37}$ The development of natural history television can be analysed as an attempt—by a group of people belonging to the middle classes, participating in the culture of amateur natural history and as such interested in the study of the behaviour of live animals in their natural surroundings - to assert the cognitive legitimacy of this pursuit, centred on the practice of observation, and to promote 'a spirit of 
enquiry, a searching curiosity about the living neighbourhood in which Man finds himself — an undramatised and exact curiosity ${ }^{38}$. Desmond Hawkins, who was to found the BBC NHU in 1957, hoped that in front of the television screen, 'the amateur student and the scientist [would] come to terms, with a possibility of general intelligibility and a shared objective ${ }^{39}$. Its promoters thus envisaged natural history television as a practice producing objects able to inhabit different social worlds. ${ }^{40}$ And the public shaping of television in the early 1950 s as a technology of public witnessing helped naturalists in their enterprise.

In television, natural history found the perfect match in terms of technology of display. Even more so than in cinema in the preceding decades, for the latter had developed as an essentially entertainment oriented medium, whereas television's informational role was prominent. ${ }^{41}$ 1953, the year when natural history television broadcast started, was marked by what has been branded a major broadcasting event-Queen Elizabeth's Coronation. ${ }^{42}$ One particular outcome of the event was to institute television technology as a means of enabling the public to visually participate in distant events, and obtain a genuine knowledge of the matter presented on the television screen.

Yesterday, for the first time in perhaps a thousand years, the Sovereign was crowned in the sight of many thousands of the humblest of her subjects. Yesterday, by penetrating at last, even vicariously, into the solemn mysteriousness of the Abbey scene, multitudes who had hoped merely to see for themselves the splendour and the pomp, found themselves comprehending for the first time the true nature of the occasion. No mere report could have impressed so strongly on those who now looked on the sense that this was a deed of dedication, in which they silently and 
reverently participated. [...] the remote spectator [...] saw more of it all, indeed, than thousands of those within the Abbey wall can have seen. ${ }^{43}$

Since its creation in the 1920 s, the BBC, which was 'set up to educate, to inform and to entertain, with a public service ethos ${ }^{, 44}$, had been as central to British public life as the Monarchy and the Church of England. Founded in 1922, it was established by Royal Charter in 1926, which ipso facto symbolically placed it above political interests and debates. Through the years, its image of impartiality, disinterestedness, and responsibility towards the British people had been consistently consolidated and it had emerged from the Second World War as the European embodiment of truth-telling and freedom of speech. ${ }^{45}$ In this context the Coronation added one more belief to those already associated with the BBC: television broadcast was 'a technology of trust and assurance that the things had been done and done in the way claimed ${ }^{46}$, it was a technology allowing for distant participation and an understanding of the true nature of things, it was the most efficient means of an enhanced and enriched vision in contrast to what a mere physical presence at the scene might have allowed. Television thus distinctly emerged as contributing to organising collective assent, allowing the constitution of 'matters of fact' by ensuring 'the multiplication of witnesses $^{47}$. Such privileging of the sense of sight over others as a means of acquiring knowledge is in line with the evolution in the modes of display in the culture of natural history, from the cabinet of curiosity where naturalia could be physically handled by visitors to natural history museums where they were locked in showcases, and could therefore only be gazed at by the public. This evolution established a natural distance between the observer and the observed, which can be said to have been further naturalised by television. ${ }^{48}$ 
The programme Look benefited fully from, and contributed to reinforcing this perception of television as a medium capable of turning a distant viewer into the direct witness of remote events. ${ }^{49}$ This appears most clearly with one film, broadcast in 1955 and which ever since has epitomised Look, Heinz Sielmann's Woodpeckers. Sielmann's film, made by replacing part of a tree trunk with glass, revealed what was happening inside a woodpecker's nest-hole. ${ }^{50}$ In the book narrating the making of the film, Sielmann declares that he had engaged in the adventure hoping 'to lay bare the secrets of the woodpeckers' nest' ${ }^{51}$, and the viewers really could feel that they had been allowed to witness previously unseen events, and that they could, as a result, obtain genuine and first hand knowledge of the true essence of this natural phenomenon. Seventeenth-century gentleman philosopher Robert Boyle devised a 'literary technology' aimed at conveying by means of words and detailed engravings enough 'circumstantial details' so as 'to trigger in the reader's mind a naturalistic image of the experimental scene ${ }^{52}$. By contrast to Boyle's literary technology, viewers were not invited to form an image in their mind so as to replicate one unique past observation, a process whose outcome is uncertain ${ }^{53}$, but were enabled by the film to conduct the actual observation themselves. And the day after the Woodpeckers broadcast, 'everyone was talking about this film where you got inside the nest ${ }^{54}$.

Claims by promoters of natural history television that they were bringing 'relief from everyday cares and anxieties ${ }^{, 55}$ by offering viewers the possibility to look 'steadily at the permanent conditions of life and [understand] the rules and patterns of animal existence ${ }^{56}$, can arguably be analysed as the assertion of natural history television's political utility on the ground of its ability to represent 'patterns of animal existence' as natural and immutable and making 
these representations largely available, thus participating in solving the problem of social order by contributing to the consolidation of 'agreed standards of values $^{57}$. The fashioning of television's social identity as a technology of public witnessing, of which, as mentioned above they took advantage, and in which they participated, allowed the promoters of natural history television in the early 1950s to claim at the same time that the new medium was a reliable source of knowledge of nature, thus enrolling the audience's support, and that it was socially useful, thus ensuring political favour.

In 1957, Desmond Hawkins celebrated the establishment of the BBC Natural History Unit - the sign that the policy conducted in Bristol under his guidance since 1953 had been ratified by the Corporation ${ }^{58}$ - by publishing The $B B C$ Naturalist, a collection of natural history essays contributed by Peter Scott and several guests to Look. ${ }^{59}$ In the introduction Hawkins celebrated the success of natural history television in terms leaving no doubts as to his confidence with respect to the reach of his achievement:

Programmes like [...] Look have shown that they can hold the attention of an audience of several millions. Such broadcasters as Peter Scott [...] enjoy a measure of popularity that would certainly not be scorned by the more orchidaceous and spectacular stars of the entertainment world.

\section{$[\ldots]$}

into those homes the $\mathrm{BBC}[\ldots]$ has brought a reliable flow of expert comment and factual report, [...] films of bird-life and animal behaviour which equip us with a range of knowledge that a Bewick or a Gilbert White might envy. ${ }^{60}$ 
Such victorious tonality, however, would not pass to the next decade, for in the 1960s, two developments occurred which both had the potential of compromising the NHU's position in terms of the production and diffusion of natural historical knowledge. These were on the one hand the rise in importance and public visibility of ethology in the early $1960 \mathrm{~s}^{61}$, and on the other the appearance in 1961 of the television series Survival on ITV. These developments forced the NHU to engage into some sort of boundary work on two fronts.

THE 1960S: SETTING THE BOUNDARIES OF NATURAL HISTORY FILMMAKING

The 1960s have been recognised as a time of flourishing and consolidation for ethology, both in terms of acceptance in the scientific sphere and in terms of public support. Part of the latter aspect can in particular be attributed to Niko Tinbergen, arrived in Oxford in 1949, who spent a lot of time in the early and mid-1950s writing books describing his approach to the study of animal behaviour for a large non-specialist public. ${ }^{62}$ It is also during this period that he trained his first students at Oxford, thus progressively extending the network of ethology, further linking the pursuit to society. ${ }^{63}$ In the second half of the $1950 \mathrm{~s}$, some of these former students became vocal public exponents of the biological study of animal behaviour. Amongst them was Desmond Morris, who from 1956 on was to host Zootime, a television programme with an important following, broadcast from the London zoo on ITV ${ }^{64}$ In this programme, Morris, Curator of Mammals at the Regent Park's Zoological Garden, would exhibit animals performing various behaviour, and scientifically interpret them for the audience. In Britain, Zootime certainly played a determining role in fashioning social 
expectations in relation to the presentation of animal behaviour on television. For it brought to the attention of a large audience the categories used to ascribe a biological meaning to animals' actions and, in line with the ethologist creed, banning subjectivist psychology and anthropomorphism when analysing animal behaviour. $^{65}$

Now the study of animal behaviour in the field had developed in the milieu of amateur natural history in the early decades of the $20^{\text {th }} \mathrm{C}$, in reaction to the development of such academic disciplines as zoology and comparative anatomy, which mainly worked with captive, or dead and stuffed animals. ${ }^{66}$ Throughout the inter-war decades, it remained practised at an "amateur" level, the few academic scientists who got involved in this pursuit, principally Julian Huxley, cultivating it on the side, more as a promising hobby than as a genuine strand in biological research. ${ }^{67}$ As the example of early natural history film-maker Cherry Kearton indicates, the unrivalled ability of field naturalists to observe undisturbed animal behaviour was one of the main supports to early natural history film-makers' claims to trustworthiness. ${ }^{68}$ To natural history, the development, in the 1950 s, of a scientific profession centred on the study of animal behaviour in the field was therefore an event comparable to what had happened in the late $19^{\text {th }} \mathrm{C}$ when the various disciplines that would form the canon of the professional life sciences were carved out of it. ${ }^{69}$ To natural history film-makers who had already adopted animal behaviour as their stock in trade, and had made the ability to capture and show it the main feature of their social identity, the blow was potentially fatal. For, with the development of a scientifically informed public discourse on animal behaviour, these film-makers could not anymore limit themselves to exhibiting films of animals behaving in 
their natural habitat unsuspicious of being observed, in order to support their claim to cognitive trustworthiness; if they wanted their films to be taken as objects of knowledge, film-makers had to find animals displaying behaviour which would illustrate the biological or evolutionary categories used by scientific practitioners studying animals in the field and reporting to the public on their observations.

In this context, the situation faced by natural history film-makers who had started working in the interwar period and were still active in the 1960s is best exemplified by the case of Armand Denis, whose series On Safari was to be decommissioned in May 1965. He had beforehand received a letter from the NHU suggesting possible changes in his way of making films:

[T]he present day television audience will not really accept this sort of pets treatment any longer. If they are going to accept it, you have really got to dress it up very carefully, both pictorially and verbally. [...] The commentary line would have to take on a more adult semi-scientific approach. People would like to know not just that you are keeping them as pets, but that you are studying them most carefully. [...] The television audience does not take too readily now-a-days to an anthropomorphic approach, i.e. pets' names etc. They want to know about animals as animals, but not so much about animals as extensions of human activity. ${ }^{70}$

In order to ensure that the NHU's output would appear more credible to the audience, its contributors were urged to relinquish any tendencies to anthropomorphism, hence abiding by a precept central to early ethology. ${ }^{71}$ Furthermore, stressing the separation between humans and animals can be 
interpreted as allowing the film-makers to highlight their straddling this specific boundary and therefore to gain in credibility.

Whilst contributors to the NHU, in reaction to the increased public visibility of ethology as the legitimate study of animal behaviour and with the hope of emulating it, were enjoined to adopt 'a more adult semi-scientific' tone, others engaged in the opposite direction. Choosing with the series Survival broadcast on ITV the way of popularisation, they started using the outcomes of this new scientific discipline to produce entertainment.

'Look created a TV climate and an atmosphere that made it possible for Survival to thrive when it arrived on the scene. ${ }^{72}$ Taking advantage of this favourable context, Collin Willock and Aubrey Buxton successfully set up Survival, in $1960^{73}$, on behalf of Anglia TV, a regional television company based in Norwich. From the start, 'leaving the specialized wood-notes-wild viewers to the $\mathrm{BBC}^{\text {, }}{ }^{\text {, }}$, the two men did not attempt to compete for the middle-class Look audience, and instead set out to attract 'the great mass of viewers [...] available in the industrial areas of the Midlands and the north ${ }^{75}$. Survival was intended to fashion natural history for the working classes. And to this end, Willock and Buxton embarked on presenting wildlife as a spectacle.

Neither of us had a scientific training. We therefore thought of our subject as natural history rather than as zoology, biology, ecology or any other combination of ologies. As writer and producer of countless Survival programmes, I have always considered this lack of scientific upbringing to be an advantage. When stuck, you can always ask scientists. There are enough of them around. The trick is to know what to ask them and then 
how to interpret what they tell you accurately and entertainingly for an audience of millions. $^{76}$

The conception of natural history guiding its creators implicitly suggested that Survival was popularised life sciences, in accordance with what would today be qualified as the classical top-down model of popularisation. ${ }^{77}$ This approach, which does not recognise natural history as a knowledge-production practice, placing it in a subservient position with regard to "ologies", was problematic for the NHU, for it could weaken the claim that natural history television was a pursuit producing genuine knowledge of the natural world, and transform the public perception of what was going on in Bristol. Suggesting on the part of the Bristol Unit a real intention of cognitively disqualifying the Survival series, and implying that the NHU's was more genuine natural history than the one presented in this series, a producer at the NHU, Jeffery Boswall, branded Survival 'Pop. Nat. Hist.' ${ }^{78}$

However, such rhetorical fencing would not be enough on the part of the NHU to discredit Survival. And in order to assert the cognitive superiority of Bristol's brand of natural history television, the NHU conspicuously developed its collaboration with scientific practitioners, following a subtle strategy designed by Desmond Hawkins in a report written in $1962 .{ }^{79}$ This document provides evidence that, faced with the competition represented by scientific practitioners of ethology in the domain of the observation of animal behaviour, the NHU perceived a necessity to fashion its programmes so as not to be vulnerable to cognitively disqualifying criticisms and as to appear credible to the audience as natural history film-making and not popularised life sciences. 
Although there are many respectable motives for an interest in wild-life (as well as some disreputable ones) the spirit of scientific enquiry must have pride of place. In handling this subject we expose ourselves to the critical scrutiny of scientists, and their approval is an important endorsement. Moreover, it is their work that throws up the ideas and instances and controversies from which programmes are made. We look to them as contributors, as source material, as consultants and as elite opinion on our efforts. In short we need their goodwill. ${ }^{80}$

It seems that this quote could be read as indicating, on the part of the founder of the NHU, an acute awareness of the boundary work to which scientific practitioners may be prone to devote themselves when non-scientists attempt to participate in the enterprise of knowledge-production, and the dire necessity to protect the NHU from it. Any ill will on the part of scientists is perceived as capable of derailing the entire project of natural history television as a practice producing genuine knowledge. At the same time, this quote also announces the relationship that progressively developed between the Unit and scientific practitioners along the 1960s and 1970s.

As we will now consider, in order to bring indisputable cognitive credibility to the NHU's output, scientific practitioners were at first enrolled in the practice of knowledge-production embodied in natural history film-making. But in a second step, their participation became limited to purveying a necessary but not sufficient ingredient to the fashioning of a performance, which, in the end, is intended to stand as a self-legitimated form of knowledge of the natural world. Progressively, the NHU actively engaged in fashioning the field scientists' social identity so as to confine them to the position of local experts, holding a local and 
limited knowledge. The moral authority of the television outlet itself would be redefined around the specific notion of the expert handling of visualising technologies, presented to the public as increasingly sophisticated, allowing for an output advertised as being of an ever growing informative quality. A key character in implementing this strategy was to be David Attenborough.

\section{SEEING IS KNOWING}

In October 1965, Attenborough wrote to Armand Denis:

When I arrived here, BBC-2 had no Natural History programme whatever, and, as you may imagine, I was anxious that it should have a regular one as soon as possible. But equally we feel it would be wrong to try to produce a carbon-copy of either "Look" or "On Safari”.

At the moment, we have scheduled a new magazine dealing with Natural History in general, from a fairly scientific point of view [...]. ${ }^{81}$

The new magazine mentioned here was a true implementation of the strategy suggested by Hawkins in his 1962 report and aimed at bolstering the trustworthiness of the NHU's output by an increased reliance on the moral authority of scientific practitioners. Life, was launched in 1965, and hosted in a studio by Dr Desmond Morris, of previous Zootime fame, and then Attenborough's major rival of the Zoo Quest period. ${ }^{82}$ Filmed in a studio in Bristol, the series repeated the principle identified in Peter Scott's programme Look, offering the possibility to practitioners in the life sciences to debate in front of the television audience:

It was a one-hour programme and it went out fortnightly from Bristol. It was done in the studio in Bristol, and I was given enough money to bring 
in experts from all over the world to discuss. And people had violently different attitudes towards animal behaviour topics. And there were some pretty fiery debates. ${ }^{83}$

Look, staging the performance of a genteel conversation between the amateur naturalist Peter Scott and his film-maker guest, had allowed for establishing the status of natural history television as a credible enterprise of production of knowledge of the natural world. This was further asserted through Life.

Life did not last. It stopped in January 1968 after 53 programmes, due to the sudden, and at the time definitive, departure of its presenter, Dr Desmond Morris, to Malta. It had, however, a lasting legacy. With the performance of the scientific debate staged every week in the Bristol studio where Life was shot, the NHU secured the good will of scientific practitioners, who were provided with a tribune from where they could publicly present and defend their work, the NHU illustrating it with specially shot sequences. ${ }^{84}$ And the three assistant producers on the set who became in the following decades prominent producers at the NHU, working amongst others on the next series, The World About Us, as well as on Life on Earth, Attenborough's opus magnum, were able, through their work on Life, to build lasting personal relationships with scientific practitioners. Thereby, beyond the public exhibition of 'visible scientists ${ }^{95}$, was ensured the continuity of the relationship between the NHU and the scientific sphere. But from then on, this relationship would happen behind the scenes and evolve so as to increase the distinction between natural history film-making and field research in the life sciences. ${ }^{86}$

From the outset, the series The World About Us was advertised as 'a series of films from all over the world about our astonishing planet and the creatures that 
live on ${ }{ }^{87}$. Like Survival, its main competitor, it was conceived as a series of films and not a studio based programme, thus breaking with what had been the dominant and traditional model of natural history television. ${ }^{88}$ This suggests, as we will see, a shift in terms of practices of legitimisation, from bringing forward trustworthy personalities such as Peter Scott or Desmond Morris, to relying exclusively on the film-making apparatus and its advertising to support claims to cognitive credibility. Given the pre-eminence attributed to the film medium, The World About Us depended heavily on film-makers specialised in wildlife. The NHU addressed the issue by finding and forming promising "amateurs", one of these being Ronald Eastman, who made himself a name with his film The Private Life of the Kingfisher (1967), which, amongst other things, showed what was happening in the bird's nest-hole, dug on a river bank. ${ }^{89}$ David Attenborough on his part, who as Controller of BBC2 had created the series and was personally supervising it, went for more significant captures. One of his early successes in this enterprise was to get Alan Root, whose work was emblematic of the Survival series, to work for the BBC. ${ }^{90}$

In 1967, Root, together with his wife Joan, had made a film for Survival about the Galapagos, Enchanted Isles, which became the first British wildlife film to be sold on the American market. ${ }^{91}$ The Roots were thus a kind of celebrities and, as Parsons indicates, their collaboration was 'valuable in adding to [the series'] prestige in the early years ${ }^{, 92}$. In December 1967, The Times readers were reminded that 'Alan Root is a Londoner, whose family emigrated to Kenya after the war. [...] a self-taught naturalist, who learnt the filming side of the job from another naturalist-cameraman Des Bartlett [...]. Joan, who was born in Kenya, is $26^{93}$. This quote establishes Alan Root in the tradition of amateur natural 
history, and also suggests that, in the late 1960s, it was admitted that to be a natural history film-maker was first and foremost to be a naturalist. Root only made two films for the NHU, but despite its brevity, the case of his collaboration with the BBC, and the way it was advertised, allows us to understand part of the role The World About Us played with respect to the ongoing problem of fashioning the NHU as an institution which could be trusted to be a reliable source of knowledge of the natural world.

Particularly illuminating in this instance is an episode which occurred during the shooting of his first film, Mzima (1969). At one point, Root got bitten by a puff adder, which prompted such a severe reaction that filming had to be postponed. The accident was mentioned in The Times and two persons were asked to react on the news. Nicholas Crocker, head of the NHU, indicated that Root was 'making a slow recovery' and that 'in his latest letter he [said] that he [hoped] to be filming again in the spring. This kind of bite is extremely dangerous and could well have been fatal ${ }^{94}$. On his part, as Controller of BBC2, who had commissioned Root's work, Attenborough commented:

We'll show the films when he's finished them: Alan's a perfectionist and I know what can happen in Africa, so I hadn't put a specific date on them. I've seen him do things that scare the life out of me, but as he spends 90 per cent of his time in the bush he knows more about its hazards than anyone. $^{95}$

A month later, The Times announced that 'Alan Root, the natural history photographer $[\ldots]$ has had to have the index finger of his right hand amputated. His right thumb is still immobile, his arm still shrivelled, and his hand badly wasted ${ }^{96}$. 
The communication around this episode appears to be illustrative of two points. The first one is that the identity of the film-maker contributing to the series The World About Us as a trustworthy individual is fashioned in ways identical to those employed by earlier natural history film-makers to support their claims to credibility. Most evidently, this unfortunate puff adder accident draws the attention to the familiar theme of bodily suffering. In addition, Attenborough's comment also mobilises the theme of the infinite patience of the daring adventurer, much used by Kearton, and Attenborough himself during his Zoo Quest period, to support their claim to knowledge making. ${ }^{97}$

Such iterations of well-worn strategies would indicate that in the late 1960s a genuine public culture of natural history film-making had been fashioned, a set of codes, beliefs, and values associated specifically with the material practice of filming wild animals in their natural habitat had been established. The second point suggested by the presentation of Alan Root's accident to the public is the clear intent on the part of the $\mathrm{BBC}$ to present, through the voice of one of its top executives, David Attenborough, the natural history film-maker as a very reliable individual whom can be let operating alone and far away in the field, in total confidence that the result will be trustworthy. Therefore somehow emerges the notion that the credibility of the natural history film-maker is vouched for by the institutional framework within which the production and diffusion of the film occurs. With respect to the making of The World About Us, this image of the trustworthy natural history film-maker stands in contrast to the presentation of participant field scientists as individuals who cannot be left alone with a camera.

One scientific practitioner who participated in The World About Us was Niko Tinbergen. His contribution resulted in the famous Signals to Survival (1968). It 
took two years to shoot the film which was meant to present 'the language of birds $[\ldots]$ their displays and what these displays meant ${ }^{98}$. The filming was conducted under the close supervision of a film-maker hired by the NHU, Hugh Falkus. And although Tinbergen actually carried the camera, he did not control it, for 'Hugh hectored and admonished and honed the script [...] really treated him [Tinbergen] like a schoolboy' ${ }^{99}$, making sure that 'no shots essential to the construction of a careful exposition were missing, ${ }^{100}$. And when it came to editing the film and constructing its sound-track (essential for a film presenting the way gulls communicate by voice and posture), Tinbergen was kept outside the editing room:

[I]n the autumn Hugh and I [Chris Parsons] met to work on the final stages of production at Bristol with the film editor, David Aliband. Then followed one of the most careful and detailed pieces of post-synchronisation yet undertaken on a wildlife film at Bristol, for we knew that the success of the programme depended largely on the accuracy of the sound track - not only for scientific purpose but also in order to create a sense of realism, of actually being in the gull colony. [...] So David, Hugh and I spent many days working long into the evenings and over weekends, before we were finally satisfied that we had recreated the sounds of the gull colony and had matched every call and wing-beat to the action in every film shot. ${ }^{101}$

The NHU was eager, for the purpose of strengthening its claims to trustworthiness, to exhibit the participation of scientific practitioners to the making of its programmes, but it was also adamant that scientific practitioners should remain in the field. Being at the same time both a field biologist and a film-maker was not possible. And when the film was mentioned in The Times on 
the occasion of the BBC winning an award with it, it was defined as 'a programme on seagulls, directed and narrated by Mr. Hugh Falkus'. ${ }^{102}$ This episode also highlights the role attributed to the mastery of the material process of making a film. Not only taking pictures with the camera, but also sound recording, cutting, editing, every aspect of the fabrication of a film is involved in this boundary work aimed at setting a clear separation between natural history film-making and field research. And as we will now see, this notion is central to the next stage of the fashioning of natural history film-making into a genuine culture of knowledge-production of the natural world, encapsulated in Life on Earth.

Presented as 'the most ambitious project of its kind ever undertaken for television $^{, 103}$, Life on Earth stands as both the outcome of what has been described so far in terms of claims to trustworthiness laid on behalf of natural history television, and the founding act of natural history television for the following decades. It turned out as a mammoth project costing GBP 1 million, and mobilising the BBC as a broadcasting institution in its entirety. It took three years to make, necessitated to put together a specially dedicated production team of thirty people from several departments, involved filming on at least a hundred locations over the world, and it engaged the help of more than 500 scientists. ${ }^{104}$

An article announcing a re-run of the series on $\mathrm{BBC} 1$ makes plain that this 'glorious explanation of Darwin's theories of evolution' ${ }^{105}$ intended to lay strong claims to knowledge on behalf of natural history film-making.

We were able, for instance, to put together views of living amphibians which no one had been able to see in that range of time ever. No zoo could show you that amount. The visual effect was devastating. It had the same 
effect on me [Attenborough] as it did on everyone else. I remember the first time I saw the amphibian programme. I was speechless. My jaw was sagging with wonder. ${ }^{106}$

Spreading before the eyes of the audience a wide sample of related organisms, the series enabled the viewers, just like the collection assembled by naturalists in their cabinet, 'to roam freely throughout the universe ${ }^{107}$ providing them with an 'overview of the natural order as a whole' ${ }^{108}$. Life on Earth transformed every domestic sitting room into a 'sedentary naturalist's study' ${ }^{109}$. The television spectators would sit in front of the television set, as naturalists would be standing in front of an open drawer in the calm enclosure of their cabinet. ${ }^{110}$

Such rhetoric asserted the cognitive superiority of the natural history television series over the zoological institution, the other place where the public, looking for knowledge of the natural world, could contemplate live creatures side by side. ${ }^{111}$ The collection of live specimens offered by the programme is meant to allow for comparisons and reach to universal knowledge through acquaintance with a multitude of particulars. ${ }^{112}$ Causing 'the spectator to see the world through new eyes ${ }^{, 13}$, Life on Earth was decidedly a wonder show. Referring to the register of awe to describe his feelings upon seeing his programme, Attenborough placed the technology used to produce the series on a transcendental level as far as he himself, and everyone else, was concerned, therefore allowing for evidences of its mastery to stand as solid ground supporting claims to expertise. ${ }^{114}$ The production of knowledge is somehow delegated to the film-making apparatus, thus rendering this knowledge incontrovertible, for it appears literally endowed with 'mechanical objectivity $^{115}$. 
Further down The Times article, Attenborough continued:

I can't tell you how touching some of the letters were. We were receiving about 100 a day. They came from children eight years old and professors of zoology. One professor wrote: "But above all, I must thank you for reminding me why it was that I became a zoologist 50 years ago." 116

In addition to providing genuine knowledge of the natural world through the panoptic vision it rendered possible, natural history television was claimed to be the genuine heir of the original 'spirit of scientific enquiry' ${ }^{117}$. This somewhat conservative assertion was reiterated in a 1984 article about The Living Planet, Attenborough's second series constructed on the model of Life on Earth.

Attenborough has identified television as the ideal vehicle for making a vast range of knowledge accessible and, most important of all, coherent. The attempt to see things as a whole has largely been abandoned by laymen and specialists alike, but Attenborough mediates between the two. $^{118}$

With Life on Earth, natural history television was endowed with the capacity of conveying genuine generalist knowledge of the natural world, allowing the audience to embrace it in its totality. At this stage, natural history television is thus seen appropriating the claim, common in the amateur naturalist tradition, to an all encompassing knowledge as opposed to the narrow view of the specialised professional scientist, somehow reviving the idea that 'those who called themselves scientists were misusing the word. It was the dedicated amateur naturalists who were more scientific than scientists ${ }^{119}$. Through this series, natural history film-making was affirmatively positioned as a self-legitimating practice of knowledge-production, in no need for external support from socially 
recognised holders of intellectual and moral authority, be they institutions such as the London Zoological Society, as was the case with Zoo Quest ${ }^{120}$, or individuals, as was the case with famous amateur naturalist Peter Scott in Look, or biologist Desmond Morris in Life. And the personality brought forward was that of a man whose trustworthy identity had been publicly fashioned on, and by natural history television, and depended on it, telenaturalist David Attenborough. As will now be discussed, the strategies employed to assert the trustworthiness of Life on Earth all foregrounded the material practice of natural history filmmaking as the source of cognitive credibility. The process of legitimisation was entirely self-contained.

In the first place, prior to the broadcast of the series, the BBC engaged in an active reshuffling of Attenborough's identity, from that of a powerful television executive back to that of the television naturalist, based on 'the performative ritual $^{, 121}$ of the television series. After his resignation from the post of director of programmes for BBC television, Attenborough regularly participated in several natural history programmes, narrating for instance episodes of The World About Us, and fronting various children programmes. The head of the NHU would for example signal that 'in weeks $41 / 42$ it looks as if there is going to be rather a large concentration of Attenborough, ${ }^{122}$ before enumerating five programmes scheduled on five different days of the week. Then Eastward with Attenborough (1973) brought him back to Indonesia, the theatre of his successful 1956 Zoo Quest for a Dragon. ${ }^{123}$ Finally, in the two years preceding the broadcast of Life on Earth, the NHU offered him to narrate the weekly episodes of its new series Wildlife on One, which, on some occasions, 'represented the largest BBC TV 
audience from any department ${ }^{124}$. Attenborough thus became the voice of natural history on British television.

The contrast with Peter Scott's Look is worth emphasising at this point. For, Scott's trustworthy status had been acquired outside the institution, and the performative ritual of Look served to reflect his trustworthiness on the institution mediating the performance, the NHU. In Attenborough's case these regular appearances hosted by a trusted institution, were meant to assert, or re-assert, his trustworthiness. His regular appearances in children programmes, in this perspective, are noticeable as an attempt to habituate the audience, from an early age, to Attenborough's ubiquitousness. Whereas in the Look scenario the legitimisation process involved external circumstances, Attenborough's rise in power announced the closure of the circle of causation. The performance's credibility was guaranteed by the performer, whose own credibility was itself guaranteed by the institution mediating the performance. All external instances of legitimisation were excluded. Life on Earth contained the sources of its own legitimisation, foremost amongst which was the presenter's performance of natural history on screen. The series was a matter not only of conveying credible knowledge but also of asserting the reliability of natural history television as a trustworthy source of knowledge of the natural world.

The beginning of the first episode of Life on Earth unambiguously sets the stage, placing from the outset the series under the cognitive and moral tutelage of British natural history's great child, Charles Darwin. Attenborough first appears standing in the South-American rainforest, then sitting on the volcanic shore of a Galapagos island. The presenter sets out to retrace Darwin's intellectual adventure, following in his footsteps. ${ }^{125}$ This introductory sequence could be 
seen as a case of natural history television claiming Darwin as its founding hero, thus asserting the intellectual credibility of the pursuit presented in the series, of which Attenborough stands as the embodiment. ${ }^{126}$ In an apparent desire to start all over again and pick things where Darwin found them, the methodological cornerstone of this pursuit is introduced in the next sequence, on fossils:

Since the discovery of radioactivity, scientists have developed techniques of measuring the age of rocks based on the rates at which some chemical elements decay. So fossils can be dated to within a few millions years. But there are much more simpler ways than that of establishing the comparative ages of rocks that anyone can use, and there is no more dramatic place to do so than in the Grand Canyon in the American West. ${ }^{127}$ Heard at an early stage in the series, this commentary further positions Life on Earth as exemplar of an enterprise of exploration of the natural world other than science, based on one methodological precept, observation. And Attenborough, going down the Grand Canyon, expertly demonstrates his gift for observation, determining the age of fossils without the help of the scientists' radioactivity. The film-maker's tone of confident certitude when delivering his commentary throughout the series, as well as the careful staging of his screen appearances ${ }^{128}$, are overall elements which can be seen as contributing to his appearing as a reliable spokesperson for nature. Yet, perhaps the most powerful of all the strategies implemented in the series to this end is what a commentator at the time characterised as

Attenborough's own intimate and enthusiastic involvement with the material. Few will forget from Life on Earth the sight of him whispering to 
camera from amidst a group of gorillas with whom he then proceeded to exchange embraces. ${ }^{129}$

This famous gorilla sequence, in the penultimate episode of the series, filmed allegedly by chance but in the end nonetheless included in the programme ${ }^{130}$, is reminiscent of the embraces witnessed in the Zoo Quest series between Attenborough and the female chimpanzee Jane, or the young orang-utan Charlie $^{131}$, all suggesting a relationship of intimacy between the presenter and wild animals. Other instances, although lesser ones, of the same strategy can be recognised for example in the opening sequence of the ninth episode, where Attenborough is seen on screen holding a platypus in his arms, or in the sixth episode when he manipulates a Goliath frog. In both cases the animals do not seem to try to escape, and these displays of a close physical contacts between the natural history film-maker and animals present the former as a bridge-builder between animals and humans, a spokesperson for the animals, one who should be trusted when imparting knowledge of them to the audience. ${ }^{132}$

All the strategies analysed so far as attempts to demonstrate the trustworthiness of the performer, and by ricochet that of the performance, rest on concealment at various degrees. For instance, prior to the shooting of the sequence where Attenborough is seen finding as by chance just the right fossil under a stone just lying there, the producer of the series had met with a scientific practitioner, 'Dr Bill Breed, Curator of Geology a the Museum of Northern Arizona' who agreed to 'accompany the crew whilst filming in the canyon'133. Similarly, the gorillas were those of a group habituated to humans by Dian Fossey, who had shown the film crew to the site where they could be found. ${ }^{134}$ We will come back to this concealment of scientific helpers at the periphery of 
the film-making process, for now suffice it to remark that in the chain of events leading to the filming of a sequence, they are always positioned at the very beginning, purveying the raw material, so to speak, but in no way involved in the making of the film, which stands as the process through which knowledge is produced, nor in the legitimisation of the series after its broadcast.

Associated to these instances of concealment, embedded in the performance itself, are strategies of exposure, mostly found in the support documentation to the series. ${ }^{135}$ As will appear, all these disclosures contribute to present the material process of filming as a means of making discoveries. For example, in a television programme for children turned into a behind the scenes look at Life on Earth, the host raised the question of being at the right place at the right time, emphasising that 'you can never be sure that animals are going to perform before your cameras'. ${ }^{136}$ The question bears on the filming of the reproductive behaviour of a frog species, Rhinoderma Darwinii. The male incubates the eggs in his vocal sacks then releases fully formed froglets from his mouth. In order to film this birth it is thus necessary to find male frogs incubating eggs, close to the release stage. One could expect Attenborough to point towards scientific practitioners advising the film crew on when and where would be the most appropriate time and place to witness this particular behaviour. Instead, it is the cameraman he brings to the fore, emphasising his outstanding patience and the importance of the camera.

Rodger Jackman is a specialist cameraman, who lives near Bristol [...] and it was he who had the fantastic job of trying to watch this frog $[\ldots]$ and he waited for 140 hours taking turns with his assistant watching the frogs, for that one moment, because if he presses the button on the camera after it's 
happened, we both know, it's too late. So Rodger watched and watched and eventually he got a shot which I don't think anybody had ever seen before. Certainly no scientist had ever seen before and certainly $I$ hadn't seen before. ${ }^{137}$

The fact that the birth of these frogs happened this way was known already ${ }^{138}$ but as Attenborough's commentary makes clear it had never been seen before by persons of authority—scientists or Attenborough—and implicitly, since it had not been seen it was not fully known. Appealing to the belief central to the culture of natural history that sight alone is enough to get a comprehensive knowledge of natural phenomena, natural history film-making is turned into a material practice allowing to unveil secrets of nature previously hidden to everyone. The appropriation by natural history film-making of the notion that discovery is the seminal moment of the production of knowledge of the natural world, embeds the practice into a Whewellian perspective ${ }^{139}$ and presents filmmakers as belonging to a 'trained elite whose expert [technical] knowledge [would give] them privileged access to natural phenomena, ${ }^{140}$.

Such fashioning of natural history film-making as a material practice allowing for the increase of the public stock of knowledge through an accumulation of successive and unexpected discoveries, appears most useful when it comes to maintaining scientific practitioners at the periphery of the film-making process. Ultimately it is the film-making apparatus which reveals the truth of nature. Scientists, when mentioned, only participate insofar as they facilitate the task of the cameramen. In a sense the relationship between natural history film-makers and scientific practitioners has become the mirror image of that which grew between life scientists and amateur naturalists when life sciences got defined as a 
specialised vocation. ${ }^{141}$ In return for their participation, scientists get 'a valuable teaching aid. Several hundred biologists had willingly helped us over the three years; it was only right that they and their colleagues should get something back from their investment ${ }^{142}$. It could be argued that natural history film-makers' boundary setting activities, with the emphasis placed on seeing, tend to erase the work of interpretation and construction of facts conducted by scientific practitioners. The NHU can thus be said to increase the distance between 'the displays and the social world of the work of research ${ }^{143}$. Natural history filmmaking in this perspective does not appear as a project leading to an increased public understanding of science, but as an enterprise of knowledge-production in its own right. Following this line of thought, it can be suggested that the observed tendency, in the BBC discourse relating to natural history film-making, to attribute a crucial responsibility in the evolution of the cognitive value of the output to what is crude technological determinism, would indicate on the part of this institution the desire to 'black box' its expertise ${ }^{144}$, so as to render it immune to questioning. And through the control it exerts on the making and diffusion of such series as Life on Earth, the NHU in Bristol stands as an institution able to 'embody meaning, create social relationships and symbolic orders"145, to constitute expertise on the natural world.

\section{CONCLUSION}

This paper first discussed how, through the series Look, the culture of natural history film-making had been successfully established on television in the 1950s and early 1960s, as a credible practice of production of knowledge of the natural world, building for this on the moral authority of the amateur naturalist Peter 
Scott. We then saw how natural history film-making had been shaped on television in the 1960s and early 1970s, as a side-effect of the increasing public visibility of the scientific study of animal behaviour in the field. In so doing, it was shown how scientific practitioners were enrolled in the film-making project and at the same time confined to the role of local experts, holders of a local knowledge. In order to support its claims to credibility the NHU first enrolled scientific practitioners and brought them to the fore, before in a second step engaging in maintaining these scientists on the periphery so as to preserve the knowledge-production aspect of natural history film-making. Lastly, by examining the context of the making and presentation of the BBC series Life on Earth we examined how natural history film-making had been consolidated into a practice of production of genuine knowledge of natural phenomena. In particular it appeared that natural history film-making on television had appropriated the claim to universality, which naturalists argued had been abandoned by professional scientists along the road towards specialisation. The NHU was thus positioned as a producer of 'boundary objects' ${ }^{146}$ that could perform an informative task for scientific practitioners and lay people alike. Following this analysis, it could be suggested that such positioning of the NHU could tend to result in a disconnecting of the work of scientific practitioners from the rest of society. The former acquiring specialised knowledge that natural history film-makers then use to produce 'working objects of knowledge,147 detached from the context of their production. In order to fashion its identity as a trustable institution able to guarantee expertise, the NHU can thus be seen interrupting the network linking scientific practitioners to society and building its own in replacement. ${ }^{148}$ 
The history of natural history film-making as it is recounted in this paper indicates that during the 1960s and 1970s, conscious efforts were made to fashion the NHU as the embodiment of a set of values and beliefs which would automatically provide a trustworthy identity to the natural history film-makers whose work was featured on the BBC channels. However, the case of natural history film-making also points towards the fact that although trustworthiness might appear to be constructed within institutions, it remains first and foremost the result of the work of identity fashioning of individuals. In this case, first naturalists anxious to give public prominence to their culture and practices, in a context where it could be superseded by others, threatening to turn natural history into mere popularised life sciences, and second individuals who, like Attenborough, had reached public prominence through a set of practices, natural history film-making, and needed to maintain the cognitive credit attached to these practices in order to maintain their own identity.

\section{Acknowledgements:}

For permission to access and publish material held at the BBC Written Archives, Reading, the author would like to thank the BBC. The research whose partial results are presented in this paper have been made possible by a $\mathrm{Ph} . \mathrm{D}$. studentship awarded by the Department of Sociology at the University of York. The author would like to thank Amanda Rees, who supervised this research. Final writing was made possible by a post-doctoral fellowship from the Max Planck Institute for the History of Science, in Berlin. Finally, the author would like to express his gratitude to David Kirby and an anonymous reviewer for their generous comments on a previous version of the text. 


\section{REFERENCES}

${ }^{1}$ BBC Press release, 10 March 2009, available online at http://news.bbc.co.uk/1/low/sci/tech/7932769.stm (last accessed 21 October 2009). I am grateful to Amanda Rees for drawing my attention to it.

${ }^{2}$ Henrika Kuklick, \& Robert Kohler, "Introduction", Science in the Field, Osiris $2^{\text {nd }}$ Series, xi (1996), 1-14, p.11

${ }^{3}$ Gregg Mitman, "Pachyderm Personalities: the Media of Science, Politics, and Conservation", in Lorraine Daston, \& Gregg Mitman, (eds), Thinking with animals, (New York, 2006), 175-195, quotes are from page 176 and 177 , respectively

${ }^{4}$ Brian Wynne, "May the sheep safely graze?", in Scott Lash, et al. (eds), Risk, Environment and Modernity, (London, 1996), 44-83, p.62

${ }^{5}$ Rosemary McKechnie, "Insiders and outsiders: identifying experts on home ground" in Alan Irwin, and Brian Wynne, (eds), Misunderstanding Science? The public reconstruction of science and technology (Cambridge, 1996), 191-212

${ }^{6}$ Jan Golinski, Making Natural Knowledge (Cambridge, 1998), 53. Such insight has been brought forward in the first place by Steven Shapin and Simon Schaffer's discussion of the establishment of experimental culture in their Leviathan and the Air-Pump (Princeton, 1985).

Such an approach to instruments has been expended by Trevor Pinch and Wiebe Bijker, amongst others, in the theorising of the social construction of technology (SCOT). See for instance Trevor Pinch and Wiebe Bijker, "The social construction of facts and artefacts", Social Studies of Science, xiv (1984), 399-441

${ }^{7}$ Thomas Gieryn, "Distancing science from religion in seventeenth-century England”, Isis, lxxix (1988), 582-593; for a discussion of the notion of institution as an analytical category in the history of science, see Golinski, Making Natural Knowledge (ref. 6)

${ }^{8}$ Jean-Baptiste Gouyon, "From Kearton to Attenborough - Fashioning the telenaturalist's identity", History of Science, xlviii (2010), (in press).

${ }^{9}$ Richard W. Burkhardt, Patterns of Behavior: Konrad Lorenz, Niko Tinbergen, and the Founding of Ethology (Chicago and London, 2005); Hans Kruuk, Niko's Nature (Oxford, 2003); Lynn K. Nyhart, "Natural History and the 'new' biology", in Jardine, N., et al. (Eds), Cultures of Natural History (Cambridge, 1996), 426-443

${ }^{10}$ Konrad Lorenz, The year of the greylag goose (London, 1979): 5 
${ }^{11}$ James A. Secord, 1996, "The crisis of nature", in Nicholas Jardine, et al. (eds), Cultures of Natural History (Cambridge, 1996), 447-459, p.449

12 Thomas F. Gieryn, "Boundary-Work and the demarcation of science from non-science: strains and interests in professional ideologies of scientists", American Sociological Review, xlviii (1983), 781-795

${ }^{13}$ See Richard Burkhardt's Patterns of behavior (ref. 9) and Hans Kruuk's Niko's Nature (ref. 9)

${ }^{14}$ Brian Regal, “Amateur versus professional: the search for Bigfoot”, Endeavour, xxxii (2008), $53-57$

${ }^{15}$ For elements on this period see Gail Davies, 'Science, Observation and Entertainment: competing visions of postwar British Natural History Television, 1946-1967', Ecumene, 7 (2000), 432-459; Christopher Parsons, True to Nature (Cambridge, 1982). Parsons' book remains the most comprehensive first hand account on this history.

${ }^{16}$ Parsons, True to Nature (ref. 15), 27

${ }^{17}$ Peter Scott, The eye of the wind, (London, 1966), 29

${ }^{18} \mathrm{Scott}$, The eye... (ref. 17), 51

${ }^{19}$ Scott, The eye... (ref. 17), 78. Scott's statement reads quite similar to David Attenborough's justifying his own leaving the university to go on television: 'Zoological research in those days was largely laboratory-bound and that wasn't the way I wanted to study animals' (David Attenborough, Life on Air, [London, 2002], 10).

${ }^{20}$ Scott, The eye... (ref. 17), 79-80. On the notion of composite, or synthetic, images, as truthfull representations of nature, see Lorraine Daston and Peter Galison, Objectivity, (New York, 2007), 81-82, and Kelley Wilder, Photography and Science (London, 2009), 32-35. I am grateful to David A. Kirby, who reviewed this paper and encouraged me to think more about this issue of wildlife painting as a prelude to natural history film-making.

${ }^{21}$ Scott, The eye... (ref. 17), 97. Original emphasis.

${ }^{22}$ Ibid.

${ }^{23}$ Ibid. The significance of natural history photography for the subsequent development of natural history films is addressed in Gouyon, "From Kearton to Attenborough..." (ref. 8). Scott's case opens up a new avenue to think about the origins of the practice of filming nature in the wild. Indeed, films can be seen as another sort of composite image, allowing to capture movement. The conception of what a truthful representation of nature is which inform natural history film-making would therefore deep part of its roots, it seems, in the ideals and aspirations animating natural history painting. In addition, Scott's parting from academic zoology can be 
analysed as a preamble to later naturalists' split from academic ethology. In both cases, distance is established through the development of an expertise in a technique of representation.

${ }^{24}$ Scott, The eye... (ref. 17), 15

${ }^{25}$ James A. Secord, Victorian Sensation (Chicago, 2000), 403

${ }^{26}$ Steven Shapin, A social history of truth, (Chicago, 1994), 38

${ }^{27}$ Shackleton, K., 1989, 'Great gifts and testing inheritance', The Guardian, 31 August 1989, 39. Incidentally, Scott's suggestion that there was a monster in the Loch Ness can be read as a rejoinder of Brian Regal's point that the quest for monsters is the preserve of amateurs naturalists as opposed to scientists (Brian Regal, “Amateur versus professional...” [ref. 14]).

${ }^{28}$ Wildscreen, 2008, 'Richard Brock-Oral History Transcription', accessible on-line at www.wildfilmhistory.org/oh/29/Richard+Brock+.html (last accessed 10 July 2008).

Attenborough quickly became an equal to Scott in terms of his status as a television naturalist, although his presence on screen began two years after Scott's, in 1955 (Gouyon, 'From Kearton to Attenborough... [ref. 8]). What happened at this time can be interpreted as the parallel development of two distinct endeavours to bring the culture of natural history to television. As a result, and during these first years, the head of BBC television ruled that Bristol should concentrate on British topics and Attenborough would have the priority on overseas ones. In 1957, Peter Scott broke the agreement by taking to Australia Charles Lagus, Attenborough's cameraman, to film footage for a programme called Faraway Look.

${ }^{29}$ See Scott, The Eye... (ref. 17) and Parsons, True to Nature (ref. 15). On the place of residence as the place of knowledge-production see Steven Shapin, "The House of Experiment in Seventeenth-Century England”, Isis, lxxix (1988), No. 3, 373-404. Scott offered Konrad Lorenz to direct research there for 'nine hundred pounds per year, plus use of Scott's boat the Beatrice' (Burkhardt, Patterns of Behavior (ref. 9), 357). Scott was thus acting as a patron of science thus further asserting his status (Golinski, Making Natural Knowledge [ref. 6]).

${ }^{30}$ Tony Soper quoted in Davies, 'Science, Observation and Entertainment... (ref. 15), 450

${ }^{31}$ James Fisher, 'Foreword', in Heinz Sielmann, My year with the woodpeckers, (London, 1959), 9-11, p. 9

${ }^{32}$ Secord, Victorian Sensation (ref. 25), 412

${ }^{33}$ Scott, The Eye... (ref. 17), 78

${ }^{34}$ Shapin, A social history... (ref. 26), 121

${ }^{35}$ Ibid.

${ }^{36}$ Shapin, op.cit (ref. 26), 121-122 
${ }^{37}$ Maurice Crosland, 'Popular science and the arts : challenges to cultural authority in France under the Second Empire', The British Journal for the History of Science, xxxiv (2001), 301-322; Bernard Lightman, Victorian Popularizers of science, (Chicago, 2007), 26

${ }^{38}$ Desmond Hawkins, (Ed.), The BBC naturalist, (London, 1957), 7

${ }^{39}$ Ibid.

${ }^{40}$ At this stage it would seem improper to call natural history films presented on television 'boundary objects' (Susal L. Star and James R. Griesemer, “Institutional Ecology, ‘Translations', and Boundary Objects", Social Studies of Science, xix (1989), 387-420), for they were not yet the result of the collaboration of allies pertaining to different social worlds. On the contrary they were very much the product of the activities of one social group, amateur naturalists, intent on being taken seriously by non-naturalist members of the public and scientists alike.

${ }^{41}$ John Corner, "General Introduction”, in John Corner, (Ed.), Popular Television in Britain (London, 1991), 1-21

${ }^{42}$ Although, as some television students emphasise (e.g.: John Corner, op. cit. [ref. 41]), seeing this single event as the sole origin of the public perception of television in post-war Britain would be unwise, the event, by its scale as well as its historical and symbolic weight at the time, should nevertheless be taken seriously when reflecting on the fashioning of television's social "identity" in the period. The television audience that day was estimated to be 20 millions, more than a half of Britain's adult population. Henrik Örnebring provides a very detailed study of how the Coronation was 'received, celebrated, and reacted to' by the audience through his examination of the Mass-Observation archive. The study reveals for instance that a conscious effort was made to ensure that as many people as possible would be able to watch the event on TV and that public viewings were organised across the country. The study insists that the Coronation was a transitional event for the privatisation and domestication of the medium television. See Henrik Örnebring, "Writing the history of television audiences. The Coronation in the Mass-Observation Archive", in Heather Wheatley, (Ed.), Re-viewing television history (London, New York, 2007), $170-183$, the quote is from page 171.

${ }^{43}$ Anonymous, "Historic Event in Television”, The Times, issue 52638 (03 June 1953), 17

${ }^{44}$ Christine Whittakker, "How the BBC pictured itself”, in Graham Roberts, and Philip M. Taylor (eds), The Historian, television, and television history, (Luton, 2001), 145-156, p.145

${ }^{45}$ Asa Briggs, The BBC, the first fifty years (Oxford, 1985)

${ }^{46}$ Steven Shapin and Simon Schaffer, Leviathan and the Air-Pump (Princeton, 1985), 60

${ }^{47}$ Shapin and Schaffer, op. cit. (ref. 46), 57

${ }^{48}$ Jonathan Crary, Techniques of the Observer (London, Cambridge, MS, 1992); Julia

Noordegraaf, 'The Emergence of the Museum in the 'Spectacular' Nineteenth Century', 
Proceedings of the Visual Knowledges Conference, The University of Edinburgh, <http://webdb.ucs.ed.ac.uk/malts/other/VKC/dsp-all-papers.cfm>

${ }^{49}$ For a discussion of the body virtually engaged and mobilised by the gaze through watching television, see Anne Friedberg's Window Shopping (Berkeley, 1993).

${ }^{50}$ For an account of the making of the film see Sielmann, My year... (ref. 31). The film can be seen on the Internet at:

http://www.wildfilmhisory.org/film/272/Peter+Scott\%3A+woodpeckers.html

${ }^{51}$ Sielmann, op. cit. (ref. 31), 59

${ }^{52}$ Shapin and Schaffer, op. cit. (ref. 46), 60

${ }^{53}$ Harry M. Collins, Changing Order: Replication and Induction in Scientific Practice (London, 1985)

${ }^{54}$ Wildscreen, 2008, "Richard Brock-Oral History Transcription” (ref. 24)

${ }^{55}$ Hawkins, BBC naturalist (ref. 38), 7

${ }^{56}$ Ibid.

${ }^{57}$ Simon Schaffer, "The Show That Never Ends: Perpetual Motion in the Early Eighteenth Century", The British Journal for the History of Science, xxviii (1995), 157- 189, p.162

${ }^{58}$ Parsons, True to Nature (ref. 15)

${ }^{59}$ Hawkins, op. cit. (ref. 38)

${ }^{60}$ Hawkins, op. cit. (ref. 38), 7

${ }^{61}$ Burkhardt, Patterns of Behavior... (ref. 9); Kruuk, Niko’s Nature (ref. 9)

${ }^{62}$ Kruuk, Niko's Nature (ref. 9)

${ }^{63}$ Bruno Latour, Science in Action (Cambridge, MS, 1987)

64 The programme, produced by Granada TV, was made and broadcast from the London zoo (from 1956 to 1965), before being moved to the Manchester zoo (until the end of the programme in 1967).

${ }^{65}$ Burkhardt, Patterns of Behavior... (ref. 9)

${ }^{66}$ David E. Allen, The Naturalist in Britain, (Princeton, 1994); Burkhardt, Patterns of Behavior... (ref. 9)

${ }^{67}$ Burkhardt, Patterns of Behavior... (ref. 9)

${ }^{68}$ Gouyon, op. cit. (ref. 8)

${ }^{69}$ Nyhart, "Natural History and the 'new' biology" (ref. 9); Secord "the crisis of Nature" (ref. 11) 
${ }^{70}$ Nicholas Crocker to Armand Denis, 25 February 1964, BBC WAC SW3/20/1 (p.2).

${ }^{71}$ Sandra D. Mitchell, “Anthropomorphism and Cross-species Modeling”, in Daston \& Mitman, Thinking (ref. 3), 100-117; Burkhardt, Patterns of Behavior... (ref. 9)

${ }^{72}$ Collin Willock, The World of Survival (London, 1978), 28

73 The first programme was broadcast in January 1961.

${ }^{74}$ Collin Willock, op. cit. (ref. 72), 27

${ }^{75}$ Parsons, True to Nature (ref. 15), 263

${ }^{76}$ Collin Willock, op. cit. (ref. 72), 10

${ }^{77}$ Roger Cooter, and Stephen Pumfrey, "Separate spheres and public places: Reflections on the history of science popularisation and science in popular culture, History of Science, xxxii (1994), 237-267; Stephen Hilgartner, “The Dominant View of Popularisation: Conceptual Problems, Political Uses”, Social Studies of Science, xx (1990), 519-539

${ }^{78}$ Collin Willock, op. cit. (ref. 72), 78. See also Derek Bousé, Wildlife films, (Philadelphia, 2000), 76

${ }^{79}$ BBC WAC, folder WE 17/2/1. Hereafter referred to as (Hawkins, 1962).

${ }^{80}$ Hawkins, 1962 (ref. 79), 7

${ }^{81}$ Attenborough to Armand Denis, 21 October 1965, BBC WAC SW3/20/1.

${ }^{82}$ It should be remarked that the inception of Life in 1965, occurs at the time when the programme Horizon started (1964), thus suggesting an overall move, on the part of the BBC, aimed at exhibiting its close ties with scientific practitioners as a resource to build up its hegemony in the televisual landscape of the1960s' Britain (Timothy Boon, Films of facts: A history of science in documentary films and television [London, 2008]).

${ }^{83}$ Wildscreen, 2008, "Desmond Morris-Oral History Transcription", accessible on-line at <http://www.wildfilmhistory.org/oh/19/Desmond+Morris.html> (last accessed 10 July 2008)

${ }^{84}$ Parsons, True to Nature (ref. 15)

${ }^{85}$ Rae Goodell, The visible scientists (Boston, 1977)

${ }^{86}$ Of course, other programmes were developed in the period, in particular Jeffery Boswall's series Private Lives and Wildlife Safaris. But none ran as long as The World About Us did, and none played such a central role in the redefinition of natural history film-making after the development of ethology.

${ }^{87}$ Parsons, True to Nature (ref. 15), 254 
${ }^{88}$ Even though, as Parsons remarks, after 1966, Look 'had moved out of the original set representing Peter Scott's studio and was [...] a series of complete films usually narrated by Peter Scott but by no means always involving him in vision' (Parsons, True to Nature [ref. 15], 263).

${ }^{89}$ Parsons, True to Nature (ref. 15)

${ }^{90}$ Alan Root started filming with the Denis and in 1959 had shot Bernhard Grzimek's Serengeti Shall Not Die which won an Oscar in 1960. For a biographical account on Alan Root covering the 1950s, 1960s and 1970s, see John Heminway, No Man's Land. The Last of White Africa, (New York, 1983),162-185.

${ }^{91}$ Bousé, Wildlife films (ref. 78)

${ }^{92}$ Parsons, True to Nature (ref. 15), 257

${ }^{93}$ PHS, “The Times Diary”, The Times, 7 December 1967, p.8

${ }^{94}$ PHS, “The Times Diary”, The Times, 2 November 1968, p.8

${ }^{95}$ Ibid.

${ }^{96}$ PHS, “The Times Diary”, The Times, 9 December, 1968, p.8

${ }^{97}$ Gouyon, op. cit. (ref. 8)

${ }^{98}$ Kruuk, Niko’s Nature (ref. 9), 232

${ }^{99}$ Ibid.

${ }^{100}$ Parsons, True to Nature (ref. 15), 262

${ }^{101}$ Ibid., italic in the original

${ }^{102}$ Anonymous, “Italia prize for BBC TV film”, The Times, 23 September 1969:6.

103 The quote is taken from the trailer shown in the Wildtrack programme included as a Special Feature on the DVD edition of the series.

${ }^{104}$ Parsons, True to Nature (ref. 15) or Attenborough, Life on Air (ref. 19), provide circumstantial narration of the way the series was made.

${ }^{105}$ Nicholas Wapshott, "The perfect teacher, back with the animals”, The Times, 1 March 1980, p.14

${ }^{106}$ Ibid.

${ }^{107}$ George Cuvier, quoted in Dorinda Outram, "New spaces in natural history", in Nicholas Jardine, et al. (eds), Cultures of Natural History (Cambridge, 1996), 249-265, p.261.

${ }^{108}$ Ibid.

${ }^{109}$ Ibid. 
${ }^{110}$ This observation could thus invite us to envisage another acceptation of the term 'telenaturalist' to include the viewers of such natural history films, who are enabled to practice natural history from a distance from the natural objects, presented on the television screen.

${ }^{111}$ And the scientific institution which granted its cognitive legitimacy to Attenborough's first ventures in the field of natural history film-making. See Gouyon, op. cit, (ref. 8).

${ }^{112}$ Daston and Galison, Objectivity, (ref. 20)

${ }^{113}$ Fred Nadis, Wonder shows: performing science, magic, and religion in America, (New Brunswick, 2005), p. xii

${ }^{114}$ Iwan R. Morus, “Seeing and Believing Science”, Isis, xcvii (2006): 101-110

${ }^{115}$ Daston and Galison, op. cit. (ref. 20)

${ }^{116}$ Wapshott, op. cit., (ref. 105)

${ }^{117}$ Hawkins, 1962 (ref. 79), 7

${ }^{118}$ Brian Appleyard, “Attenborough goes back to nature”, The Times, 19 January 1984, p. 10

${ }^{119}$ Regal, "Amateur versus professional..." (ref. 14). 56

${ }^{120}$ Gouyon, op. cit. (ref. 8)

${ }^{121}$ Sheila Jasanoff, "Breaking the Waves in Science Studies", Social Studies of Science, xxxiii (2003), 389-400, p. 396. For a discussion of the format of the television series as a narrative form, see for instance John Ellis, Visible Fictions (London, 1992)

${ }^{122}$ Mick Rhodes to Controller BBC1 and Controller BBC2, 13 June 1973, BBC WAC, Folder WE $8 / 83 / 1$

${ }^{123}$ Gouyon, op. cit., (ref. 8)

${ }^{124}$ Parsons, True to Nature (ref. 15), 351

${ }^{125}$ In a programme broadcast on 1 February 2009, 'Charles Darwin and the Tree of Life', which he narrated on BBC1, Attenborough was similarly seen sitting in Darwin's study, manipulating Darwin's stuffed finches, walking in Darwin's garden, and so on, somewhat impersonating the naturalist without any costume.

${ }^{126}$ Secord, "The crisis of Nature" (ref. 11)

${ }^{127}$ Commentary Life on Earth Episode 1 'The Infinite Variety', BBC, 1979 (11:03-11:27). The numbers between brackets indicate, in minutes and seconds, at what point in the episode the quote can be found, using the DVD of the series published in 2005 by the BBC.

${ }^{128}$ Parsons, True to Nature (ref. 15).

${ }^{129}$ Appleyard, op. cit. (ref. 118) 
${ }^{130}$ Parsons, True to Nature (ref. 15); Attenborough, Life on Air (ref. 19). For a very vivid first hand account of the filming of the sequence, see the "oral history transcription" of Martin Sounders, the cameraman who filmed it. Wildscreen, 2008, "Martin Saunders-Oral History Transcription", accessible on-line at <http://www.wildfilmhistory.org/oh/14/Martin+Saunders.html> (last accessed 10 July 2008)

${ }^{131}$ Gouyon, op. cit., (ref. 8)

132 James Serpell \& Elisabeth Paul, "Pets and the development of positive attitudes to animals", in Manning \& Serpell (eds), Animals and Human society, (London, 1994), 127-144; Bruno Latour, Politics of Nature (Cambridge, MS, 2004)

${ }^{133}$ Parsons, True to Nature (ref. 15), 330

${ }^{134}$ Wildscreen, 2008, "Martin Saunders-Oral History Transcription” (ref. 130)

${ }^{135}$ Morus, "Seeing and Believing...” (ref. 114)

${ }^{136}$ WildTrack, with Tony Soper, BBC1, February 1979, (08:19)

${ }^{137}$ Wild Track, with Tony Soper, BBC1, February 1979, (08:50-09:40) Attenborough's emphasis on " $I$ " in the end of the commentary is in the original.

${ }^{138}$ Parsons, True to Nature (ref. 15)

${ }^{139}$ Richard Yeo, Defining Science: William Whewell, natural knowledge, and public debate in early Victorian Britain (Cambridge, 1993)

${ }^{140}$ Iwan R. Morus, Frankenstein's Children: Electricity, Exhibition, and Experiment in Early Nineteenth-Century London (Princeton, 1998), 4

${ }^{141}$ Allen, The Naturalist... (ref. 66); Secord, "The crisis of Nature” (ref. 11)

${ }^{142}$ Parsons, True to Nature (ref. 15), 349

${ }^{143}$ Secord, "The crisis of Nature" (ref. 11), 455

${ }^{144}$ Latour, Science in Action (ref. 63)

${ }^{145}$ Sheila Jasanoff, Designs on Nature (Princeton, 2005), 27-28

${ }^{146}$ Susan Leigh Star, and James R. Griesemer, "Institutional Ecology, (ref. 40)

${ }^{147}$ Daston and Galison, op. cit. (ref. 20)

${ }^{148}$ Latour, Science in Action (ref. 63) 